\title{
VIABILIDADE DA UTILIZAÇÃO STENTS METÁLICOS BIODEGRADÁVEIS*
}

\section{Resumo}

\author{
Paula Rodrigues Caumo ${ }^{1}$ \\ Renan Luis da Silva ${ }^{2}$ \\ André Tavares ${ }^{3}$ \\ Diego Pacheco Wermuth ${ }^{3}$ \\ Lirio Schaeffer ${ }^{4}$
}

\begin{abstract}
A aterosclerose é um termo geral relativo a diversas doenças relacionadas ao espessamento e perda de elasticidade da parede arterial. Atualmente os maus hábitos alimentares, combinados ao sedentarismo, podem levar a ocorrência de elevados níveis de colesterol na corrente sanguínea. Este fato aumenta o risco de obstrução dos vasos sanguíneos, limitando o fluxo do sangue para o coração. Desta maneira, para desobstruir o vaso sanguíneo e manter o lúmen arterial aberto é colocado um stent. Os stents são redes, normalmente de ligas metálicas, que servem para desobstruir os vasos sanguíneos. $\mathrm{O}$ tratamento de doenças das artérias coronárias e periféricas usando stents metálicos tem sido adotado nas intervenções médicas nos dias de hoje. No entanto, surgiram argumentos que indicavam os benefícios de remover o stent após este ter feito a desobstrução, originando desenvolvimento de stents biodegradáveis. Estes exigem propriedades mecânicas adequadas, biocompatibilidade adequada, garantindo uma baixa toxicidade dos produtos de degradação. Com isso, o objetivo deste trabalho é o estudo preliminar sobre stents metálicos biodegradáveis, como ferro puro, magnésio. Além disso, avaliar se os mesmos são adequados para aplicação à stents biodegradáveis, avaliando as propriedades mecânicas dos metais, biocompatibilidade e toxicidade dos compostos degradados ao longo do tempo de implantação.
\end{abstract}

Palavras-chave: Aterosclerose; Biodegradável; Ferro; Stent.

\section{VIABILITY FOR USE METAL BIODEGRADABLE STENTS}

\begin{abstract}
The atherosclerosis is a general term for several diseases related to thickening and loss of elasticity of the arterial wall. Currently the bad eating habits, combined with physical inactivity can lead to occurrence of high levels of cholesterol in the bloodstream. This fact increases the risk of obstruction of the blood vessels, limiting the flow of blood to the heart. This way, to clear the blood vessel and maintain the arterial lumen open is placed a stent to assist the flow of blood.

The stents are networks, usually of metal alloys, which serve to clear the blood vessels. The treatment of diseases of the coronary arteries and peripheral using metallic stents have been adopted in medical interventions in today. However, there have been arguments that indicated the benefits of removing the stent after it has done the clearing, that led to the development of biodegradable stents. These require appropriate mechanical properties, biocompatibility, ensuring a low toxicity of the products of degradation. The objective is the preliminary study on biodegradable metallic stent. In addition, metals properties such as ductility, yield and tensile strength, adequate biocompatibility and low toxicity of the compounds degraded all along the time of deployment.

Keywords: Atherosclerosis; Biodegradable; Iron; Stent.

1 Graduanda de Eng. Metalúrgica, Bolsista, Laboratório de Transformação Mecânica (Ldtm), UFRGS, Porto Alegre, Rio Grande do Sul, Brasil.

Mestrando, Engenheiro de Produção, Estudante, Ldtm, UFRGS, Porto Alegre, RS, Brasil.

3 Doutorando, Mestre em Processo de Fabricação, Bolsista, Ldtm, UFRGS, Porto Alegre, RS, Brasil.

4 Doutor em Processo de Fabricação Mecânica, Professor/Coordenador, Ldtm, UFRGS, Porto Alegre, RS, Brasil.
\end{abstract}




\section{1 - INTRODUÇÃO}

A aterosclerose, que afeta parte da população mundial, é um termo geral relativo a diversas doenças onde é observado o espessamento e perda de elasticidade da parede arterial. Atualmente os maus hábitos alimentares, combinados ao sedentarismo, podem levar a ocorrência de elevados níveis de colesterol na corrente sanguínea. A aterosclerose pode gerar a estenose, que nada mais é que o estreitamento anormal de um vaso sanguíneo. Quando o grau de estreitamento se torna alto o suficiente para impedir a passagem do sangue, torna-se necessária uma intervenção para devolver o grau de passagem sanguíneo pelo vaso [1]. Suas manifestações dependem do local que a doença compromete. Entre as doenças estão: infarto ou angina quando acomete as artérias coronárias, dor e claudicação em membros inferiores quando acomete as pernas e, por fim, acidente vascular cerebral quando compromete as carótidas. Para desobstruir a parede arterial é feito um processo chamado de Angioplastia Coronária ou Intervenção Coronária Percutânea (Figura 1), que é um tratamento não cirúrgico das obstruções das artérias, por meio de um cateter balão para aumentar o fluxo de sangue.

A restenose que é a recorrência da estenose pode ocorrer dentro de três a seis meses após uma angioplastia, dentro de uma faixa de 30 a $60 \%$ dos casos, o mecanismo básico da ocorrência de restenose está associado à proliferação de células, seguida de expansão extracelular, contudo a biologia básica envolvida, ainda é objeto de pesquisas. Com o objetivo de reduzir o percentual desta doença, é feito a implantação de stents, que são redes que tem a finalidade de manter o interior do vaso aberto, liberando normalmente o fluxo sanguíneo. Deste modo, utilizando estes dispositivos a taxa de ocorrência da restenose se localiza entre 15 a $30 \%$ dos implantes ${ }^{[2]}$.
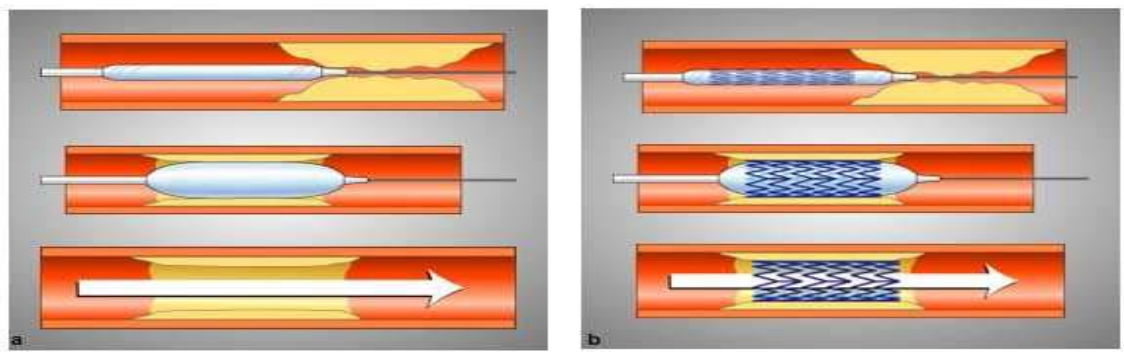

Figura 1: Esquema da sequência da técnica de angioplastia. - a) procedimento de uma angioplastia sem colocação do stent, b) procedimento de uma angioplastia com colocação do stent [5]. Fonte: OLIVEIRA, Carla. Comportamento de proteínas em stents vasculares modificados por pulverização catódica. 2009. 79 pág. Tese (Mestrado Integrado em Engenharia Biomédica) Faculdade de Ciências e Tecnologia da Universidade de Coimbra, Coimbra, 2009.

Com as falhas encontradas pelos stents metálicos, diferentes tipos de materiais, morfologias e técnicas têm sido pesquisados para a fabricação e o implante de stents. Um exemplo disso são os stents biodegradáveis, que são materiais de origem naturais ou sintéticos adequados para substituir ou tratar tecidos naturais do corpo e dos órgãos em interação com sistemas biológicos. Deste modo, o desenvolvimento de materiais biodegradáveis que se degradam no corpo ganham importância nas pesquisas. Para um material ser implantado no corpo humano, este precisa ser considerado biocompatível, no qual deve atender uma série de características em termos de propriedades físicas, mecânicas (dureza e ductilidade), microestruturais, químicas, resistência à corrosão. 
Com isso, o objetivo deste trabalho é o estudo e aplicação de metais, como material biodegradável para aplicações cardiovasculares, avaliando suas vantagens e desvantagens de aplicação à degradação corpórea, e se o mesmo apresenta propriedades mecânicas, como ductilidade, rendimento e resistência à tração, adequada biocompatibilidade e baixa toxicidade dos compostos degradados todos ao longo do tempo de implantação.

\section{1 - Tipos de Stents Coronários}

O stent coronário é uma prótese metálica endovascular. Podem ser em: espiral, são flexíveis, entretanto frágeis, de bobina, são mais flexíveis ainda e de malha que são uma combinação dos stents em espiral e de bobina.

Os stents coronários inovaram o campo de cardiologia intervencionista e a sua implantação tornou-se modelo de auxílio para desobstruir o fluxo sanguíneo. Os stents coronários desenvolvidos até o presente momento podem ser divididos em quatro categorias: metálicos, metálicos revestidos, bioabsorvíveis e cobertos com fármacos ${ }^{[3]}$.

\subsection{1 - Stents Metálicos}

Stents metálicos expansíveis por balão necessitam ter a característica de sofrer deformação plástica e após, manter a mesma dimensão. De modo geral devem apresentar [4]:

1- Boa razão de expansão, uma vez que a órtese é implantada e o balão é inflado, deve expandir com relativa facilidade, se conformando de acordo com a parede do vaso;

2- Suficiente resistência radial, e retração mínima, para resistir à tensão;

3- Imposta pela parede do vaso aterosclerótico sem romper ou ceder excessivamente;

4- Suficiente flexibilidade, para facilitar seu deslocamento através das artérias até a implantação;

5- Adequada radiopacidade;

6- Biocompatibilidade;

7- Capacidade de dopagem com medicação (no caso dos stents cobertos com fármacos);

Os materiais frequentemente empregados para fabricação de órteses endovasculares, são o aço Inoxidável AISI 316-L, Ligas Cr-Co, Ti, Ni-Ti, PLA, CoPolímero Poli Ácido Láctico (PLA) - Poli Ácido Glicólico (PGA), ferro puro e as ligas de magnésio ${ }^{[4]}$.

\subsection{2 - Stents Fármacos}

Os stents farmacológicos são dispositivos similares a uma mola, como comentado anteriormente, difere-se dos outros convencionais por ser revestido de medicamentos anti-inflamatórios e imunossupressores que tem como objetivo desentupir as artérias do coração. Este tipo de stent apresenta medicações em suas estruturas, no qual esses remédios são liberados nos primeiros 12 meses de implante, com a ideia de diminuir a chance de o vaso sanguíneo fechar outra vez. Nos convencionais, que possuem apenas a estrutura metálica, sem medicações, ocorre maior risco de, nos primeiros 12 meses de implante, o vaso fechar mais uma vez.

Uma das vantagens do stent farmacológico comparando-se ao uso do stent 
tradicional (feito de metal) é a liberação de medicação com o objetivo de diminuir a chance de nova estenose ou fechamento do vaso.

\subsection{3 - Stents Biodegradáveis}

Pesquisas no campo de biomateriais têm cada vez mais sido aperfeiçoado e inovado. Esta divisão particular de biomateriais é dada para implantes com uma função temporária, tal como órteses endovasculares, também chamadas de stents [5]. Stents fabricados com materiais biodegradáveis constituem uma inovação tecnológica, pois estes dispositivos tem o objetivo de desobstruir o vaso até que o mesmo volte ao normal e após isso o stent se degrade progressivamente .

\subsubsection{1 - Stents Poliméricos Biodegradáveis}

Os polímeros são utilizados como excipientes em manipulações normalizadas de medicamentos e cosméticos, no qual o polímero pode ser usado como substância, diferenciada do fármaco, que tem sua segurança avaliada e, a partir de então, pode ser incluso na forma farmacêutica, com intenções variadas, tais como, ajudar na preparação; oferecer estabilidade física, química e microbiológica ao produto; confirmar a aceitabilidade do paciente.

Polímeros biodegradáveis podem ser interpretados como aqueles que passam por degradação macromolecular in vivo, por acontecimento de enzimas, microorganismos ou células [6,7]. A palavra biodegradação determina os processos envolvendo quebra de cadeia e modificações da massa molar e da solubilidade do polímero. Processos biológicos, físicos e químicos, podem atuar na biodegradação $[8,9]$.

Foram prosseguidos os primeiros sistemas implantáveis para liberação de fármacos. Diversos polímeros, biodegradáveis são utilizados no preparo de sistemas implantáveis, os biodegradáveis mais empregados são o Poli Ácido Láctico (PLA), o Poli Caprolactona (PCL) e o Poli Ácido Lático-co-ácido Glicólico (PLGA). ${ }^{[10,11] .}$

\section{2 - Stents metálicos biodegradáveis}

A seguir veremos o mecanismo de degradação de órteses endovasculares metálicas biodegradáveis.

\subsection{1 - Mecanismo de degradação}

Mecanismo degradação generalizada do modo típico de degradação na Biomassa Microbiana (BMS) é através de um processo de corrosão. A corrosão, geralmente procede de uma reação eletroquímica com eletrólito a produzir óxidos, hidróxidos, gás hidrogênio, ou outros compostos.

A Figura 2 mostra a degradação do Biometal (BM) em um ambiente fisiológico, imediatamente após o Biometal (BM) entrar em contato com o organismo, ele entra em degradação. Estas reações ocorrem de forma arbitrária sobre toda a superfície onde se forma um acoplamento galvânico devido a diferentes potenciais entre o metal e a fase intermetálica, ou contorno de grão, como mostrado na Figura 2 (a). Simultaneamente, as moléculas orgânicas, tais como proteínas, aminoácidos e lipídios, será adsorvido sobre a superfície do metal, influenciando assim a dissolução da BM. O ambiente fisiológico é altamente agressivo, especialmente devido à alta concentração de íons cloreto, no qual normalmente é fatal para a camada protetora de hidróxido metálico. Cloreto de adsorção provoca a degradação do metal e leva a corrosão localizada. 

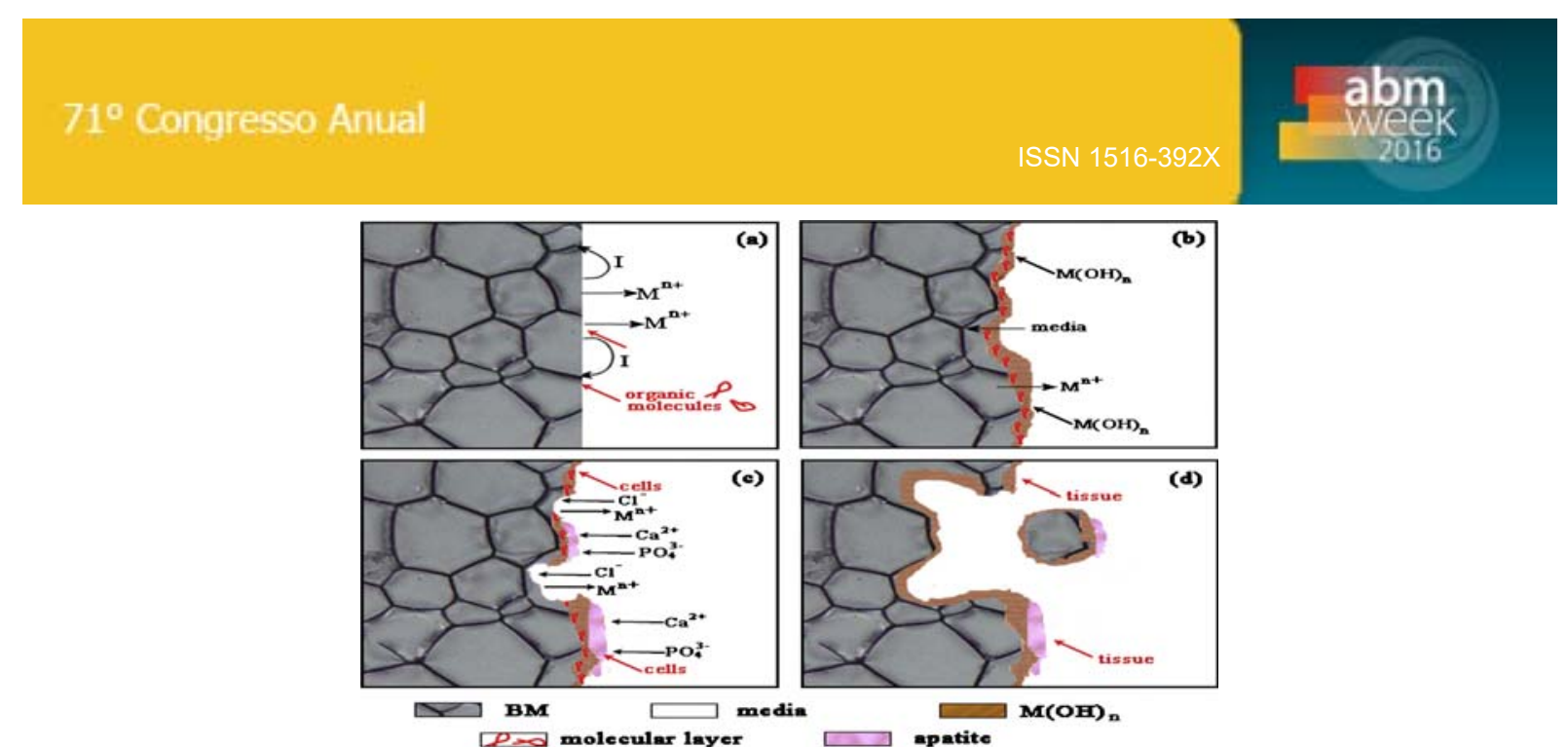

Figura 2 - Degradação de metais em ambiente fisiológico. Fonte: OLIVEIRA, Carla. Comportamento de proteínas em stents vasculares modificados por pulverização catódica. 2009. 79 pág. Tese (Mestrado Integrado em Engenharia Biomédica) Faculdade de Ciências e Tecnologia da Universidade de Coimbra, Coimbra, 2009.

\subsection{2 - Metais puros Biodegradáveis}

Esta categoria inclui os metais, com níveis de impureza menor do que o comercial dos limites de tolerância. As taxas de corrosão de metais biodegradáveis em esta categoria são principalmente impulsionadas pela incluído vestígios de impurezas.

\subsubsection{1 - Ferro puro (Fe)}

Atualmente, ferro puro e magnésio são os metais mais utilizados para a fabricação de stets coronários metálicos bioabsorvíveis. Stents de ferro puro ultrapassam $99,5 \%$, em massa, de ferro.

$O$ processo de degradação do ferro envolve a oxidação do Ferro $(\mathrm{Fe})$, como foi estudado anteriormente. A aplicabilidade do ferro puro se tornou interessante, pois, reduz nos casos estudados, o risco de trombose e não apresenta toxicidade localizada. Na Figura 3 está presente uma amostra de ferro puro, no qual a mesma foi colocada em meio aquoso, fluido corpóreo, conhecido como solução de Hank. Está amostra permaneceu 33 dias para análise de sua biodegradação.

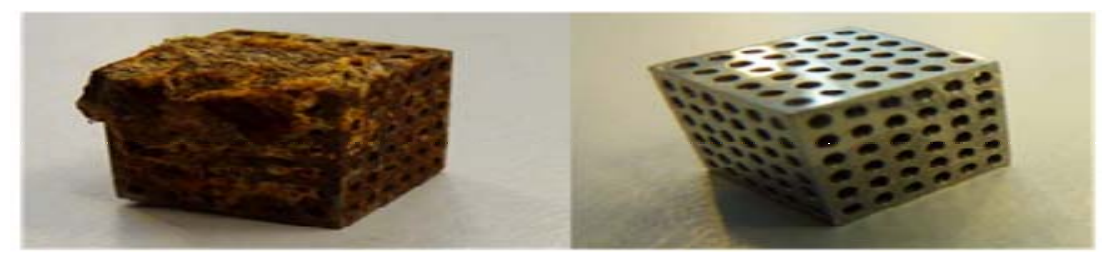

Figura 3 - Amostras ensaiadas em meio corpóreo simulado. a- amostra ensaiada por 33 dias e bamostra de referência. Fonte: MOLEMAN, J. W. A study on Biodegradable iron Model Scaffolds. Master Thesis. 2012., Vol. Delft University of Technology.

\subsection{3 - Ligas Biodegradáveis}

Liga biodegradável engloba metais biodegradáveis com diferentes microestruturas e um ou mais elementos de liga. Tendo em vista as preocupações com a biosegurança dos produtos de corrosão, os elementos de liga e as respectivas quantidades devem ser controlados sem causar efeitos adversos e efeitos fisiopatológicos e farmacológicos.

A liga ferro-magnésio vem sendo alvo de grandes pesquisas neste campo de aplicação, pois o magnésio é um metal que possui rápida degradação. Ligando-se magnésio e ferro, obtemos uma liga com um tempo de degradação adequada para certos casos de aterosclerose, no qual o ferro tem uma degradação em torno de 12 meses quando implantado. 


\section{3 - Implantações do Ferro Puro em mamíferos}

A seguir veremos resultados que foram encontrados na literatura, que mostram o comportamento de tubos de ferro puro implantados em mamíferos e o comportamento de outros metais e ligas até então estudados.

As primeiras aplicações do magnésio foram em implantes ortopédicos bioabsorvíveis. Porém, estes materiais têm sido utilizados em órteses endovasculares coronários. Para aplicação em stents, às propriedades mecânicas e resistência à corrosão do magnésio puro não são suficientes, por este motivo a liga Ferro- Magnésio (Fe-Mg) adquire propriedade adequadas para utilização em stents.

Pesquisas mostram a degradação de um tubo de ferro puro com parede de 0,2 $\mathrm{mm}$ e $5 \mathrm{~mm}$ de comprimento em mamíferos de laboratório. Essas dimensões se aproximam das dimensões de órteses reais. A Figura 6 mostra a degradação do tubo de ferro puro após 3 e 9 meses de implantação, Figura 6-a e 6 b, respectivamente. [3]
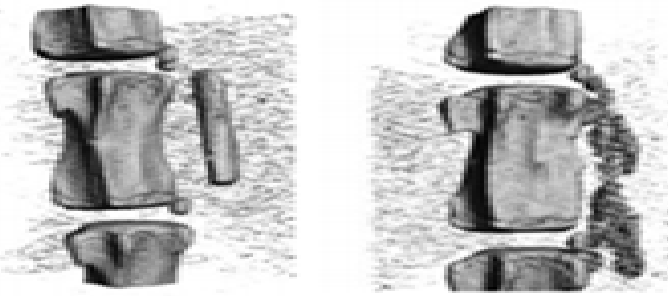

Figura 6 - Degradação do tubo de ferro puro após a-3 e b- 9 meses de implantação Fonte: Adaptado de Mueller e colaboradores. 2012 (57).

A amostra implantada durante três meses (a) apresenta pites e pequenos orifícios, evidenciando o início da corrosão, enquanto a amostra retirada após nove meses apresenta-se completamente degradada, restando somente material granular. $\mathrm{O}$ resultado é um apanhado do mesmo experimento realizado em 17 animais. Os autores reportaram que os produtos de transformação do ferro são absorvidos pelo corpo, causando limitada irritação no tecido em contato com o implante, de forma a ser degradado no período acima citado, que é o período recomendado para os implantes de endopróteses bioabsorvíveis.

Foi encontrado por Mantovani [13] que a alta relação área/volume favorece a maior taxa de degradação do ferro puro no organismo. A lenta cinética de degradação é um dos fatores que limitam a utilização deste material em implantes bioabsorvíveis. Estes resultados sugerem que a utilização de componentes sinterizados, os quais apresentam alta relação área/volume podem ser indicados para aplicação em endopróteses bioabsorvíveis de ferro puro.

Outros autores ${ }^{[14]}$ observaram que as reações inflamatórias observadas se devem em maior parte ao processo de cura, não sendo observado em excesso de reações iônicas do ferro. Devido à degradação do ferro no tecido, região próxima ao implante, o ferro corroído circula no corpo através da circulação sanguínea. A acumulação de ferro em órgãos foi detectada apenas em poucas células e não foi associada a processos inflamatórios.

Pesquisas mostram que foi desenvolvida uma liga metálica contendo $\mathrm{Fe}-35 \% \mathrm{Mn}$ pelo processo de metalurgia do pó e avaliaram o perfil de degradação e as propriedades mecânicas do material sinterizado. Os autores reportaram que as propriedades mecânicas da liga estudada são comparáveis às do aço inoxidável AISI 316L, também utilizado como material para a fabricação de órteses endovasculares. Ainda verificou-se que a liga Fe-35\%Mn sinterizada a partir de pós- 
elementares apresentam maior taxa de degradação em meio biológico em comparação ao ferro puro.

\section{4 - Implantações do Magnésio}

A implantação em pacientes humanos apresentaram resultados positivos em alguns casos e negativos em outros. Teoricamente, o magnésio não possui as propriedades mecânicas mais adequadas para sua aplicação em órteses endovasculares e seu comportamento de degradação não é controlável [15]. Apesar de a toxicidade não significar um problema para o caso das órteses de magnésio, um estudo com ênfase na interação entre material e meio fisiológico deve ser realizado para melhor controle dos efeitos da implantação em longo prazo.

As ligas de magnésio são utilizadas em aplicações biomédicas devido entre outros fatores, ao seu módulo de Young, semelhantes as dos ossos e sua propriedade de bioabsorção pelo organismo. No entanto, sua rápida degradação no meio corpóreo humano implica na limitação das suas aplicações clínicas. Adicionalmente, os elementos de liga comumente utilizados para aumento das propriedades mecânicas do magnésio estão ligados a diversas reações adversas do organismo. Por exemplo, no tratamento de recém-nascidos com disfunções cardíacas, foi reportado que o emprego de terras raras em órteses bioabsorvíveis de base magnésio não foi tolerado.

\section{2 - MATERIAIS E MÉTODOS}

Nesta seção será brevemente visto a caracterização de materiais utilizados para o desenvolvimento de protótipos de órtese endovascular (stent), utilizando como meio de conformação a micromoldagem de pós-metálicos por injeção. Mais detalhes sobre o processo estão relados em TAVARES, A.C. (2014) ${ }^{[12]}$. O ferro puro foi o material utilizado para o desenvolvimento das cargas injetáveis, para a obtenção de tubos.

\section{1 - Procedimentos Experimentais}

Para o desenvolvimento de órteses de metais biodegradáveis, são necessários certos cuidados. A homogeneização do material deve ser extremamente cautelosa, sem presença de fases indesejadas, pois o organismo pode processar, e em muitas vezes agindo como contaminante.

Conforme a literatura ${ }^{[12]}$ foi caracterizada misturas injetáveis para a obtenção dos corpos de prova, em forma cilíndrica (tubos), e posteriormente serão usinados para originar os stents ${ }^{3}$.

\section{2 - Prototipagem de stents de ferro puro}

Conforme dados a bibliografia [12], uma das características importantes para a para órteses de metais biodegradáveis é a morfologia do pó. Após se determinar as quantidades percentuais em massa de cada componente a ser misturado, foi feito a preparação de misturas injetáveis, visando à obtenção de tubos com dimensões micrométricas para a produção de stents, mediante moldagem de pós por injeção.

Conforme TAVARES, A.C. (2014) ${ }^{[12]}$ foram estudadas algumas formulações distintas, as composições que foram utilizadas como polímeros estruturais: o 
polipropileno (PP), o polietileno de baixa densidade linear (PEBDL), o polietileno de alta densidade (PEAD), como polímero a auxiliar de fluxo a parafina (PW) e cera de carnaúba, como agente surfactante (SA) tendo comoo objetivo da pesquisa é se avaliar as diferentes características geradas pelos hidrocarbonetos contidos nas misturas, tendo sido empregado nestas o mesmo percentual volumétrico de pó metálico $62 \%$ a fim de se determinar a melhor composição de veiculo. Após os materiais misturados, estes foram analisados e avaliados quanto suas características. As misturas que apresentaram os melhores resultados foram levadas a uma máquina injetora, Arburg Allrounder 170S, com um molde contendo quatro cavidades de corpos de prova (Figura 5) distintos.

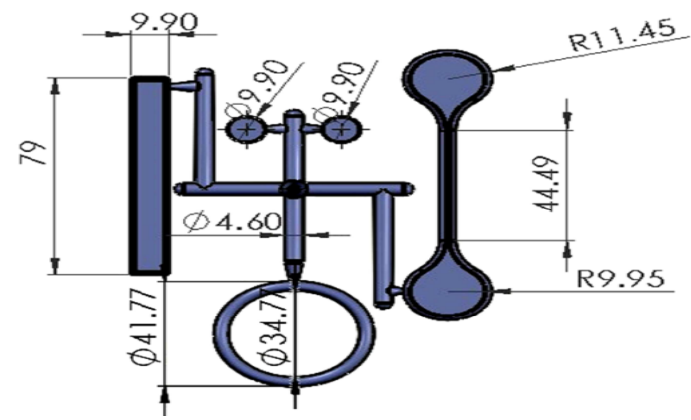

Figura 5 - Distribuição de canais do moldado dos corpos de prova empregado. Fonte: TAVARES A; MARTINS V. et. al.. Uso da moldagem de pós por injeção para obtenção de stents biodegradáveis. INOVTEC 2014.

\subsection{Extração química}

Após o material ser injetado, é feito a extração química no qual é uma técnica bastante empregada em sistemas ligante óleo-polímero ou cera-polímero, como é o caso das empregadas nesta pesquisa. O solvente deve dissolver apenas o óleo (ou a cera), deixando assim poros abertos para uma subsequente extração térmica.

\subsection{Extração térmica}

Depois de feito a extração química, é feito o processo de remoção térmica, no qual a mesma pode ser feita por degradação, evaporação, ou empregando um substrato poroso absorvente. A técnica utilizada no laboratório de transformação mecânica foi por aquecimento controlado do moldado desde a temperatura ambiente até em torno de $600{ }^{\circ} \mathrm{C}$ sob uma atmosfera de gases inertes, redutores ou oxidantes, podendo também ser vácuo.

\subsection{Sinterização}

Após a extração térmica, as amostras foram encaminhadas para sinterização, em um forno convencional até uma temperatura de $1100{ }^{\circ} \mathrm{C}$. A sinterização é um processo no qual pós, uma vez compactados, são submetidos a temperaturas elevadas, ligeiramente menores que a sua temperatura de fusão. Este processo cria uma alteração na sua estrutura microscópica com o objetivo de dar resistência às peças. Após este processo, os corpos injetados estão prontos para serem usinados e darem forma ao stent. 


\section{RESULTADOS E DISCUSSÃO}

De forma geral o projeto de um material bioabsorvível deve evitar a utilização de elementos com potenciais problemas toxicológicos ou se seu uso for inevitável, deve-se manter o mínimo teor aceitável ${ }^{[15]}$. Outro importante parâmetro a ser levado em consideração é o processamento deste material, que não deve ser demasiadamente complexo, o que dificulta a avaliação in vivo, bem como posterior melhoria da eficiência do processo. Frequentemente tem-se utilizado zinco como elemento de liga para elevação das propriedades mecânicas e para o aumento da resistência a corrosão em órteses endovasculares de magnésio.

No presente momento a pesquisa encontra-se na obtenção do material sinterizado, tento com uma das principais dificuldades à elaboração de uma matriz complexa que na obtenção da peça, a mesma contemple as resistências mecânicas pertinentes á implementação no in vivo, principalmente a elasticidade posterior a todos os processos de sinterização.

\section{CONCLUSÃO}

Através do trabalho desenvolvido foi concluído que a utilização de metais biodegradáveis para desenvolver órteses endovasculares é viável e possível, e cada vez mais esse campo de pesquisa vem-se expandindo. O principal problema da utilização destes dispositivos está associado à implantação de qualquer biomaterial no corpo humano, e a reação adversa que o organismo pode ter, impedindo o correto funcionamento de próteses e implantes. Desta maneira, metais como ferro puro, magnésio e outros elementos metálicos da tabela periódica são de grande importância para a área da medicina, pois até uma determinada quantidade, o corpo humano não apresenta rejeição.

O ferro puro possui propriedades mecânicas adequadas, biocompatibilidade adequada, garantindo uma baixa toxicidade dos produtos de degradação. Seu tempo de degradação, como visto anteriormente, é de aproximadamente nove meses, tempo ideal para um stent biodegradável. Em alguns casos específicos não é viável a sua aplicação, devido a sua prolongada degradação, no qual, é um dos fatores que limitam a utilização deste material em implantes bioabsorvíveis. Deste modo, a ligas metálicas biodegradáveis estão em grande utilização, podendo-se obter através da união de metais, o tempo adequado para casos específicos de aterosclerose, além de atingir propriedades mecânicas vantajosas.

Já o magnésio não possui as propriedades mecânicas mais adequadas para aplicação em órteses endovasculares e seu comportamento de degradação não é controlável. Porém quando há a necessidade que a degradação do stent seja acelerada a utilização de magnésio é viável.

\section{REFERÊNCIAS}

1. TAVARES, André. Desenvolvimento de orteses cardivasculares metálicos biodegradáveis de ferro puro obtidas via moldagem de pós-metálicos por injeção. 2015. 77 pág. (qualificação para obtenção do grau de doutor em Engenharia). Escola de Engenharia Programa de Pós-Graduação em Engenharia de Minas, Metalúrgica e de Materiais (PPGE3M).

2. GRUNTZIG AR, SENNING A, SIEGENTHALER W.E. Nonoperative dilatationof coronaryartery stenosis: percutaneous transluminal coronary angioplasty. J. Medicine. 1979, Vol. 301, pp. 61-68. 
3. M. MORAVEJ, A. PURNAMA, M. FISET, J. COUET, , D. MANTOVANI. Electroformed pure iron as a new biomaterial for degradable stents: In vitro degradation and preliminary cell viability studies. Acta Biomaterialia. 2010, Vol. 6 , pp. 1843-1851.

4. GARG, S., PATRICK W. SERRUYS, M. Coronary Stents . Current Status Journal of the American College of Cardiology. 10, 2010, Vol. 56.

5. MOLEMAN, J. W. A study on Biodegradable iron Model Scaffolds. Master Thesis. 2012., Vol. Delft University of Technology.

6. WOLOSKER, NELSON. Evolution of infrapopliteal artery stenting. Jornal Vascular Brasileiro. 3, 2008, Vol. 7, pp. 191-192.

7. Evolution of Stents: past, present and future. Rev. Cardiovasc. Ther. 7, 2009, Vol. 5, pp. 443-446.

8. SUSAWA T, SHIRAKI K, SHIMIZU Y. . Biodegradable intracoronary stents in adult dogs. J Am Coll Cardiol. 1993, Vol. 21:, p. 483.

9. Van der GIESSEN, J., LINCOFF AM, SCHWARTZ RS, VAN BEUSEKOM HM, SERRUYS PW, HOLMES JR DR, ET AL. Marked inflammatory sequelae toimplantation of biodegradable and nonbiodegradable pol-ymers inporcine coronary arteries. Circulation. 1690 -1697, 1996, Vol. 94.

10. LANDIN, ANDRÉ., GOMES, RENATA., et al. Equipamentos e tecnologias para saúde: oportunidades para uma inserção competitiva da indústria brasileira. Complexo Industrial da Saúde. Março, 2013, Vol. 37, BNDES Setorial, pp. 173-226.

11. SERRUYS PW, DE JAEGERE P, KIEMENEIJ F, et al., for the Benestent Study Group. A comparison of Balloon-expandable-stent implanta-tion with balloon angioplasty in patients with coronary artery disease. Jornal of Medicine, 331:489-95.1994. Vol. 331.

12. TAVARES A; MARTINS V. et. al.. Uso da moldagem de pós por injeção para obtenção de stents biodegradáveis. INOVTEC 2014.

13. HERMAWAN H, PURNAMA A, DUB E D, COUET J, MANTOVANI D. Fe-Mn alloys for metallic biode-gradable stents: Degradation and cell via-bility studies. Acta Biomaterialia. 2010, Vol. 6, pp. 1852-1860.

14. SUMITA M, TEOH SH. Durability of metallic implant materials. engineering materials for biomedical applications. ., 2004, pp. 2-1-2-31.

15. GARG, S., PATRICK W. SERRUYS, M. CORONARY STENTS . Current Status Journal of the American College of Cardiology. 10, 2010, Vol. 56. 